\title{
Oligopoly Equilibria "à la Stackelberg" in Pure Exchange Economies ${ }^{1}$
}

\author{
Ludovic A. Julien \\ Fabrice Tricou *
}

\section{$1 \quad$ Introduction}

The concept of oligopoly competition introduced by Stackelberg (1934) has mainly been developed in production economies under partial equilibrium analysis (Anderson and Engers (1992), Friedman (1983), Tirole (1988) and Vives (1999)). The Stackelberg equilibrium may be conceived as a perfect Nash equilibrium of a two stage game under perfect information, where each player moves in a prescribed order (Kreps (1990)). This paper aims at extending the analysis of oligopolistic competition proposed by Stackelberg to a general equilibrium framework.

We here propose to develop the concept of Stackelberg equilibrium in the context of a pure exchange economy, without tackling the problems of existence and uniqueness ${ }^{2}$. The general equilibrium competition $\grave{a}$ la Stackelberg can easily be captured by this simple framework, and the structure of a pure exchange economy is sufficient to display the diversity of behaviors and of interactions associated to this complex form of competition ${ }^{3}$. Additionally, we assume the individual positions and the timing of moves as given, and therefore do not question the way a specific agent could or should become a leader (see Amir and Grilo (1999)). Two interesting features can be put forward when casting Stackelberg competition into a general equilibrium framework. First, the market demand addressed to the pro-

EconomiX, Université Paris Ouest-Nanterre La Défense, Bureau K116, 200, avenue de la République, 92001 Nanterre Cédex, ludovic.julien@u-paris10.fr, fabrice.tricou@u-paris10.fr

1 A first version of this paper was presented at the conference "Economics of information" that held at the University of Paris X in June 2007. We acknowledge R. Breton, B. Crettez and P.A. Jouvet for their remarks. We are especially grateful to an anonymous referee whom suggestions improved the quality of the paper.

2 The existence and the uniqueness analyses are beyond the scope of this paper. The existence of general oligopoly equilibrium usually raises specific problems (Bonnisseau and Florig (2003), Gabszewicz (2002)).

3 Moreover, the pure exchange analysis enables to avoid the problem encountered about the normalization of prices for production economies (Gabszewicz and Vial (1972)). 
ducers is made endogenous, which overcomes the lack of micro-foundations that occurs with the usual assumption of an exogenous market demand function. Second, asymmetries across interrelated markets are integrated, while they cannot be captured in partial equilibrium analyses, which can only feature asymmetries on an isolated market.

The different notions of oligopoly equilibrium can be distinguished by the degree of asymmetry they display. According to the competition ' $\grave{a} l a$ Walras', all the individuals behave the same non strategic way and all the sectors work the same perfect way. This double symmetry does not stand with the competition 'à la Cournot': an asymmetric treatment of the sectors is introduced, some being oligopolistic and others staying competitive (Gabszewicz (2006)). But the symmetry remains in the treatment of every individual on a given sector, or a given side of the market. When the competition ' $a ̀$ la Stackelberg' is introduced, a double asymmetry is possible: between the oligopolistic and the competitive sectors, and moreover between the leader and the follower(s) inside the oligopolistic sector, or on the same side of the market. It is then possible to combine a relative advantage for one sector upon another (i.e. an uneven distribution of market power among the sectors) and a relative advantage for an agent upon another (i.e. an uneven distribution of market power among the agents of a given sector). Correlatively, two or three kinds of behavior are involved in the market interactions $\grave{a}$ la Stackelberg: an active leader and some reactive followers, and possibly many passive price-takers.

In order to emphasize the working and the consequences of market power, we analytically rely on the framework of oligopolistic competition initially developed by Codognato and Gabszewicz (1991), (1993), and later pursued by d'Aspremont et al. (1997), Gabszewicz and Michel (1997) and in Gabszewicz (2002), (2006). Additionally, we also refer to the strategic market game framework initially proposed by Shapley and Shubik (1977) and notably developed by Sahi and Yao (1989) and also by Codognato and Ghosal (2000). We thus introduce Stackelberg competition in general equilibrium analysis under two kinds of market price mechanism. In the Cournot-Walras approach, the equilibrium prices are determined for any given strategies, and then the oligopolists' strategies are decided. In the strategic market game approach we select, the relative prices are consistent and given by a market clearing mechanism.

Two concepts of Stackelberg general equilibrium are proposed: the Stackelberg-Walras Equilibrium and the Stackelberg-Cournot Equilibrium. We first give two general definitions in a simple general framework with $L$ goods, and then explore these concepts in a two-commodity economy. We obtain several results about asymptotic identifications and welfare comparisons considering these equilibria and some usual equilibria: the CournotWalras, the Cournot and the Walras equilibria. Firstly, when the number 
of agents tends to infinity, the Stackelberg-Cournot equilibrium identifies with the Stackelberg-Walras equilibrium. Secondly, there is no Pareto domination between the Stackelberg-Walras and the Stackelberg-Cournot equilibria. Moreover, when the market power is the same for each oligopolist, there is no Pareto domination between the Stackelberg equilibria and the Cournot equilibria. Finally, we display a general ranking in terms of prices and of exchanged quantities involving the four strategic equilibria and the competitive equilibrium.

The paper is organized as follows. Section 2 proposes two definitions in a $L$-good economy: one for the Stackelberg-Walras equilibrium and the other for the Cournot-Stackelberg equilibrium. Section 3 gives an example for a two commodity economy in which the results are shown.

\section{The Stackelberg general equilibrium concepts: two definitions}

Consider a pure exchange economy with $L$ divisible consumption goods $\ell$, $\ell=1,2, \ldots, L$, and $H$ agents $h, h=1,2, \ldots, H$. Let's note $U_{h}\left(x_{h}\right)$ the utility function of agent $h$, which represents her/his preferences among the consumption bundles $x_{h} \in I R_{+}^{L}$. For all $h, U_{h}($.$) is continuous, increasing$ in its arguments and strictly quasi-concave.

We suppose that each consumer owns a quantity of only one consumption good. To simplify, assume that agents 1 to $n_{1}$ hold initial endowment of good 1 , agents $n_{l-1}+1$ to $n_{l}$ own some good $\ell$ and agents $n_{L-1}+1$ to $n_{L}=H$ possess quantities of good $L$. Additionally, we assume an asymmetric property of goods, as good 1 is heterogeneously scattered among few individuals, whereas the other goods are distributed among many agents. We thus consider the following distribution of initial endowments among agents:

$$
\begin{gathered}
\omega_{1}=\left(\omega_{11}, \ldots, 0, \ldots, 0\right) \text { and } \omega_{e}=\left(\omega_{31}, \ldots, 0, \ldots, 0\right), h=2, \ldots, n_{1}, \\
(\ldots,) \\
\omega_{e}=\left(0, \ldots, \omega_{t}, \ldots, 0\right), h=n_{l-1}+1, \ldots, n_{i}, \\
(\ldots,) \\
\omega_{2}=\left(0, \ldots, 0, \ldots, \omega_{k i}\right), h=n_{h-1}+1, \ldots, H .
\end{gathered}
$$

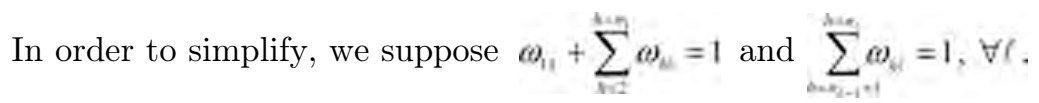


We here assume that agent 1 is the leader and that agents $h$, with $h=2, \ldots, n_{1}$, are followers, whereas all the other agents act either strategically or competitively.

Two concepts of Stackelberg equilibrium can be defined, depending on the type of competition at work in the other sectors ${ }^{4}$. We here focus on the cases where in the other sectors agents are either price-takers or Cournotian oligopolists. The resulting equilibria are the Stackelberg-Walras equilibrium (SWE) in the former case and the Stackelberg-Cournot equilibrium (SCE) in the latter case.

\subsection{The Stackelberg-Walras equilibrium}

Let $p=\left(p_{1}, p_{2}, \ldots, p_{L}\right)$ be the price system, where each price is expressed in terms of a numéraire. Each agent $h$ endowed with good $\ell$ owns a nominal wealth $p_{\ell} \omega_{h \ell}$. Agent $h$ uses a fraction of this wealth to trade it for the $L-1$ other goods.

The strategic behavior consists in contracting the quantity of the owned good brought to the market. The strategy sets thus write:

$$
\begin{aligned}
& S_{1}=\left\{s_{11} \in I R \mid 0 \leq s_{11} \leq \omega_{11}\right\} . \\
& E_{n}=\left\{e_{\mu_{1}} \in I R, \mid 0 \leq e_{\mu_{1}} \leq \omega_{31}\right\}, h=2, \ldots, n_{1} \text {, } \\
& E_{h}=\{\}, h=n_{1}+1, \ldots, H \text {, }
\end{aligned}
$$

where $s_{11}$ and $e_{h 1}$ denote the pure strategies of agent 1 and of agent $h, h=2, \ldots, n_{1}$. For $h=n_{1}+1, \ldots, H, z_{h \ell}$ denotes the competitive supply of $h$ in $\ell$. Each strategy set is defined on the real line, so it is convex. As a closed (and bounded) interval, it is compact.

Let's present the logic of the SWE. Agents having endowments in every good different from good 1 act competitively, whereas the other agents behave strategically for good 1 and competitively for the other goods. The leader manipulates the followers' decisions and all these oligopolists manipulate the price, while the many other agents behave competitively.

This equilibrium concept can be modeled as a sequential structure in three steps ${ }^{5}$ : it is based on a two-stage game which relies on a competitive moment. The game is played under complete information. Information is perfect for the leader, but imperfect for each follower since, when s/he makes her/his own decision, s/he knows the previous decision of the leader but ignores the simultaneous decisions of the other followers. The story is solved

4 We could also have three types of behavior within sector 1 when more than two agents interact in it: at least two agents can compete 'à la Stackelberg', the others acting competitively. For analytical conveniences, this case is not here considered.

5 We here consider that the competitive behavior is given, and not the consequence of a Cournotian game, as it is the case in Busetto et al. (2008). 
by backward induction. Before the strategic interactions, the general equilibrium deduced from the competitive behaviors is computed for any value of each strategy. Then, in the first strategic step, the followers' reaction functions are determined. Finally, in the second strategic step, the leader's optimal decision is made ${ }^{6}$.

A SWE is thus a non cooperative equilibrium of a game where the players are the oligopolists, the strategies are their supply decisions and the payoffs are their utility levels.

The competitive plans are determined for any given strategies $s_{11} \in S_{1}$ and $e_{h 1} \in E_{h}, h=2, \ldots, n_{1}$. For a price system $p$, the non-strategic maximization programs write:

$$
\begin{aligned}
& \operatorname{Mar} U_{1}\left(\omega_{11}-s_{11}, \ldots, x_{1 /}, \ldots, x_{12}\right) \text { s.t. } \sum_{n=0} p_{1} x_{11} \leq p_{1} s_{11}, W_{s_{11}} \in S_{1},
\end{aligned}
$$

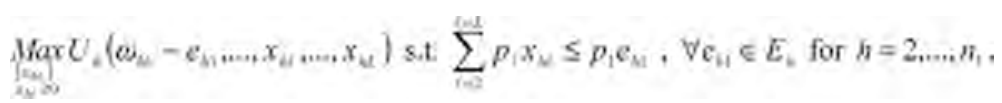

$$
\begin{aligned}
& (\ldots)
\end{aligned}
$$

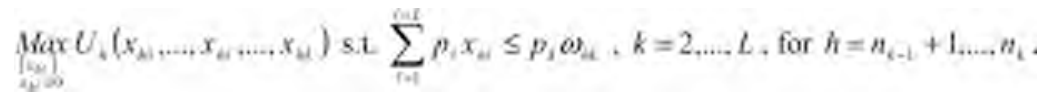

These programs give the $H L-n_{1}$ demand functions, each of them depending on all the prices and endowments ${ }^{7}$. The demands of oligopolists also depend on their strategies. Notice that $x_{11}=\omega_{11}-s_{11}$ and $x_{h 1}=\omega_{h 1}-s_{h 1}, \quad h=2, \ldots, n_{1}$, are not competitive demand functions, while $x_{h k}=\omega_{h k}-z_{h k}, h=n_{k-1}+1, \ldots, n_{k}$, are competitive demand functions. Denote by $x_{h}=x_{h}\left(p, \omega_{h l}\right)$ the solution to $(7)$, and respectively by $x_{1}=x_{1}\left(p, s_{11}, \omega_{11}\right)$ and by $x_{h}=x_{h}\left(p, e_{h 1}, \omega_{h 1}\right)$ the solutions to (5) and (6). By the assumptions made for each utility function and by $\omega_{h l}>0$, these solutions exist and are unique if $p \gg 0$.

The equilibrium price system $p\left(s_{1}, \varepsilon_{2}, \ldots, \varepsilon_{s, 1}: \epsilon_{1}, \ldots, \epsilon_{n}\right)$ is the solution of the following system of equations ${ }^{8}$ :

$$
\begin{aligned}
& \sum_{n=1} x_{11}(p, \omega)=s_{11}+\sum e_{n 1} \\
& (\ldots) \\
& x_{n}\left(p, s_{11}, \omega_{11}\right)+\sum_{n=1} x_{21}\left(p, e_{21} \cdot \omega_{11}\right)+\sum_{n=1}^{\mu} x_{n}\left(p, \omega_{n}\right)=\sum \omega_{n}
\end{aligned}
$$

\footnotetext{
6 In a given two-agent game, the order of play can be considered as the result of agents' own preplay timing decisions. Following this view, the type of moves (sequential or simultaneous) as well as the assignment of roles to the players could be endogenous (Amir and Grilo (1999)). Alternatively, the order of play can be conceived as the ranking of the agents in terms of market power, the leader being the 'biggest' agent.

7 The demand functions are homogenous of degree zero in absolute prices: they depend on relative prices.

8 This system determines $L(L-1) / 2$ equilibrium relative prices.
} 


$$
\begin{aligned}
& \text { (...) }
\end{aligned}
$$

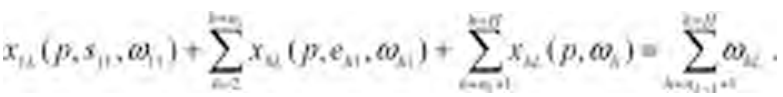

The properties of the utility functions, the fact that $\omega_{h l}>0$ and the assumptions made on the strategic sets together guarantee a solution to (8), that is the existence of an equilibrium price system. We additionally suppose that this general equilibrium is unique. In what follows, we shall denote the price system by $p\left(s_{11}, c_{11}, \ldots, \varepsilon_{n-1}\right)$, dropping the exogenous initial endowments. This equilibrium price system is actually manipulated by the leader and the followers through their strategic supplies of good 1 .

The strategic plan of any follower is determined by two elements: s/ he manipulates the equilibrium prices and s/he takes the leader's strategy and the $\left(n_{1}-2\right)$ other followers' strategies as given. Thus each follower's program can be written, for any $h=2, \ldots, n_{1}$ :

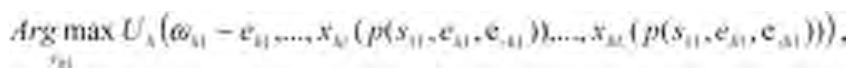

where $\mathrm{e}_{-h 1}$ is the vector of best responses of all the followers different from $h$. This yields the following reaction function $\phi_{h}$, where $\phi_{b}: S_{1} \times E_{-j}^{n-7} \rightarrow E_{h}$ :

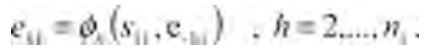

It is assumed that the functions $\phi_{h}$ are continuous and differentiable. Additionally, two basic configurations hold: there are strategic complementarities when $\partial \phi_{1} / \partial s_{11}>0$ and $\partial \phi_{1} / \partial c_{-4}>0$, where $e_{-h 1}$ is the - $h$ th component of the vector $\mathrm{e}_{-h 1}$; and strategic substituabilities when these two inequalities are reverse.

The strategic plan of the leader is determined by two elements: s/he manipulates the equilibrium prices and all the followers' strategies. Hence, the leader has to solve the following system of $\left(n_{1}-1\right)$ equations, which determines a mutual consistency among the best-responses, for any given value of $s_{11}$ :

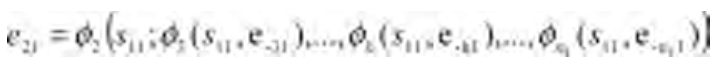

$$
\begin{aligned}
& (\ldots)
\end{aligned}
$$

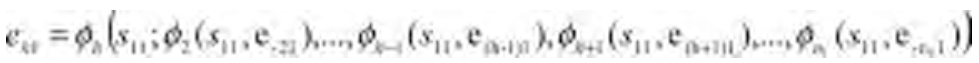

$$
\begin{aligned}
& (\ldots) \\
& e_{\mathrm{si}}=\phi_{\mathrm{s}_{2}}\left(s_{11} ; \phi_{2}\left(s_{11}, \mathrm{e}_{-21}\right) \ldots, \phi_{3}\left(s_{11}, \mathrm{e}_{-31}\right), \ldots, \phi_{\mathrm{s}-1}\left(s_{11}, \mathrm{e}_{-\left(\mathrm{s}_{1}-511\right.}\right)\right) .
\end{aligned}
$$

We assume that (11) has one solution, given by $e_{h 1}=c_{11}\left(s_{11}\right), h=2, \ldots, n_{1}$. The leader thus solves the program:

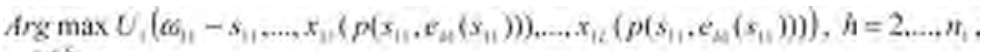

$$
\begin{aligned}
& \text { (1) }
\end{aligned}
$$


which gives the optimal strategy $\tilde{s}_{11}$.

It is then possible to determine the followers' strategies $\widetilde{e}_{i 1}=e_{i 1}\left(\widetilde{s}_{i 1}\right)$ and the vector of SWE prices $\widetilde{p}=\widetilde{p}\left(\widetilde{S}_{i, 1}, \widetilde{e}_{2}, \ldots, \widetilde{e}_{j}\right)$. The SWE allocations fol-

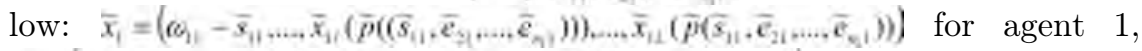

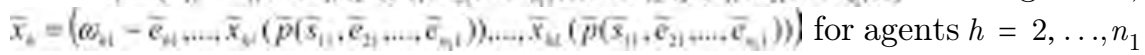
and finally $\vec{x}_{\mathrm{A}}=\left(\bar{x}_{\mathrm{u}}(\bar{p}), \ldots, \hat{o}_{\mu}-z_{\mathrm{u}}(\bar{p}) \ldots, \bar{x}_{\mathrm{u}}(\bar{p})\right)$ for agents $h=n_{1}+1, \ldots, H$. Finally, the associated utility levels are $\widetilde{U}_{d}\left(\tilde{x}_{\mathrm{s}}\right), \forall$. It is now possible to state a formal definition for the SWE:

Definition 1. A Stackelberg-Walras equilibrium is given by a $n_{1}$-tuple of strategies $\left(\widetilde{s}_{1}, \widetilde{e}_{3,}, \ldots, \widetilde{e}_{01}\right) \in I R^{\eta}$, a price system $\widetilde{p}=p\left(\widetilde{s}_{11}, \widetilde{e}_{11}, \ldots, \widetilde{e}_{n}\right)$ and an allocation $\left(\tilde{x}_{i}, \ldots, \tilde{x}_{A} \ldots \ldots, \tilde{x}_{n}\right) \in \mathbb{R} \mathbb{R}^{\prime \prime \prime}$ such that the five following conditions hold:

$$
\begin{aligned}
& \text { (i) } \widetilde{x}_{A}=x_{i}\left(\widetilde{p}_{i} ; \widetilde{s}_{11}, \widetilde{e}_{21}, \ldots, \widetilde{e}_{4} ; ; \sigma_{4}\right), \forall h_{4} \\
& \text { (ii) } \sum \tilde{x}_{\mu}=\sum \omega_{k}, \mathrm{w} \text {, }
\end{aligned}
$$

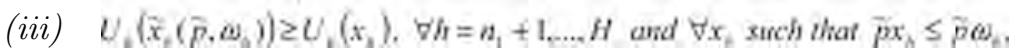

$$
\begin{aligned}
& \text { (iv) } U_{A}\left(\bar{x}_{2}\left(\bar{p} ; \bar{s}_{11}, \bar{e}_{\mu,}, \bar{e}_{2 H}, \omega_{2}\right)\right)
\end{aligned}
$$

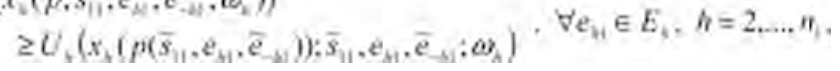

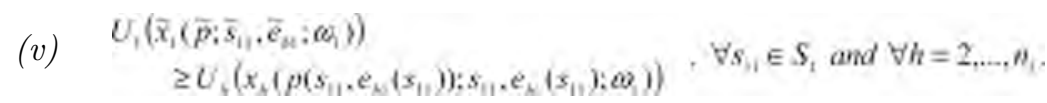

\subsection{The Stackelberg-Cournot equilibrium}

Each agent $h$ owning good $\ell$ now uses fractions of her/his initial endowment to trade them for the $(L-1)$ other commodities. The strategic behavior then involves all the fractions of the owned good that are engaged in exchange of all the other goods. The strategy sets thus write:

$$
\begin{aligned}
& s_{1}=\left\{s_{11} \in \mathbb{R} R_{+}^{2-1} \mid 0 \leq \sum_{i=1} s_{11} \leq \omega_{11}\right\} .
\end{aligned}
$$

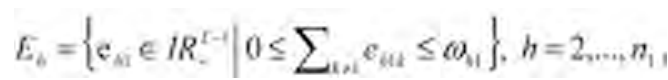

$$
\begin{aligned}
& E_{b}=\left\{\mathrm{e}_{\mu} \in\left|R_{*}^{L-1}\right| 0 \leq \sum_{\omega, \lambda} e_{t+\alpha} \leq \omega_{t}\right\}, h=n_{l-1}+1, \ldots, n_{i}, \forall i \neq 1,
\end{aligned}
$$

where $s_{11 k}$ (resp. $\mathrm{e}_{h \ell k}$ ) is the component of vector $s_{11}$ (resp. $e_{h l}$ ) corresponding to good $k$. The bid $s_{11 k}$ indicates the amount of commodity 1 the leader offers in exchange for commodity $k, \forall k \neq 1$. And the bid $e_{h l k}$ indicates the amount of commodity $\ell$ each follower $h$ endowed with $\ell$ offers in exchange for commodity $k, \forall k \neq \ell$.

Let's present the logic of the SCE. Here, all agents behave strategically, with agent 1 as the manipulating leader. The followers are not only 
the other agents endowed with good 1, but also the agents endowed with every other good, who now behave oligopolistically.

That equilibrium concept can be modeled as a sequential structure in two steps. The game is played under complete information. Information is perfect for the leader, but imperfect for each follower, as the followers play simultaneously. The game is solved by backward induction, considering first all the strategic reactive decisions of the followers, and then the strategic active choice of the leader.

A SCE is a non cooperative equilibrium of a game where the players are the oligopolists, the strategies are their supply decisions and the payoffs are their utility levels.

Technically, we rely on the strategic market game mechanism proposed by Shapley and developed by Sahi and Yao (1989), and also by Codognato and Ghosal (2000), since it generates consistent relative prices ${ }^{9}$. Our own framework nonetheless displays two specificities. First, we assume a unimodal structure of endowments; so bids form a vector, and not a matrix. Second, we assume that every agent offers but not demands the good s/he owns; so bids form a vector made of $(L-1)$ and not $L$ components.

For any given $H$-tuple of strategies, a price vector $p$ is market-clearing if $p \in I R_{++}^{L}$ and if the following system is satisfied:

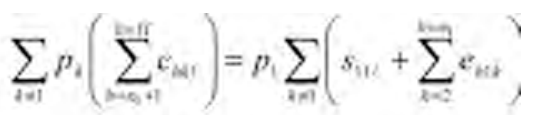

$$
\begin{aligned}
& \text { (...) }
\end{aligned}
$$

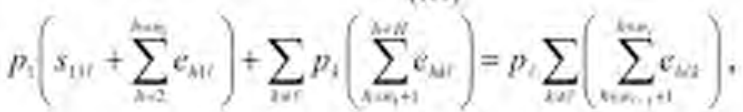

$$
\begin{aligned}
& \text { (...) }
\end{aligned}
$$

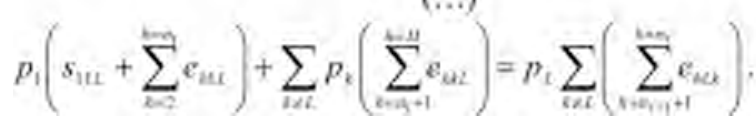

These conditions stipulate that the aggregate value of all goods supplied to buy any commodity $\ell$ must be equal to the aggregate value of this good $\ell$ supplied to buy any other commodity. We suppose that the marketclearing price system $p\left(\mathrm{~s}_{\|+}+\mathrm{e}_{21+\ldots,} \mathrm{e}_{\mu}+\ldots, \mathrm{e}_{\mu}\right)$ exists and is unique.

The strategic plan of any follower $h$ is determined by two elements: $\mathrm{s} /$ he manipulates the $(L-1)$ relative prices, and $\mathrm{s} /$ he takes the leader's vector of bids $s_{11}$ and the $(H-2)$ other followers' vectors of bids $b_{3}=\left(e_{21}, \ldots, e_{1-1 i}, e_{b+1 i}, \ldots ., e_{w}\right)$ as given. Therefore, each follower's program can be written:

9 For a survey on these problems, and more generally on strategic market games, see Giraud (2003). 


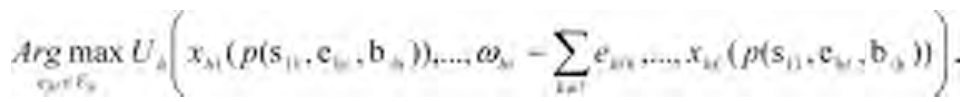

This yields the vector of reaction functions $\zeta_{4}: S_{1} \times E^{N-v} \rightarrow E_{*}$, where the component $e_{h \ell k}$ of $\mathrm{e}_{\mathrm{h} \ell}$ gives the best response of $h$ for each good $k$, $k \neq \ell$ :

$$
\mathrm{c}_{\mathrm{ik}}=\zeta_{\mathrm{M}}\left(\mathrm{s}_{11}, \mathrm{~b}_{\mathrm{a}}\right), \forall h=2, \ldots . H .
$$

It is assumed that the functions $\zeta_{h \ell}$ are continuous and differentiable.

The strategic plan of the leader consists in manipulating the market clearing relative prices and the followers' strategies. Therefore, the leader solves the following system of $(H-1)(L-1)$ equations with $(H-1)(L-1)$ endogenous variables $e_{h \ell k}$ :

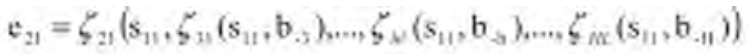

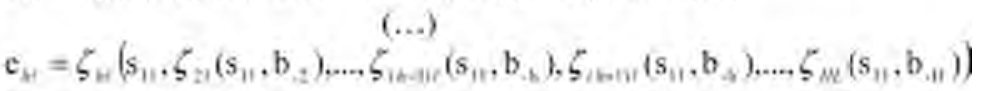

$$
\begin{aligned}
& (. .)
\end{aligned}
$$

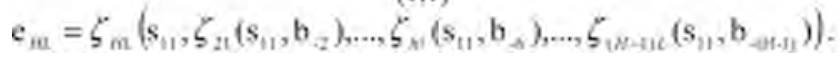

This system determines a mutual consistency among the best-responses, for any given vector of bids $s_{11}$ of the leader. We assume that (19) has one solution, depending on $s_{11}: \mathrm{e}_{\mathrm{h} \ell}=\mathrm{e}_{\mathrm{h} \ell}\left(s_{11}\right), \forall h=2, \ldots, H$. The leader thus solves the program:

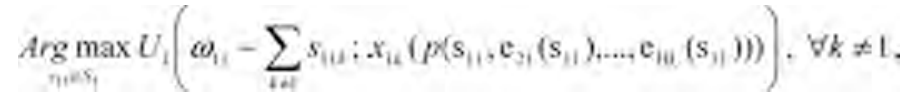

which yields the vector of optimal bids $\hat{s}_{11}$.

It is then possible to determine the vector of bids of all follower: $\hat{\mathrm{e}}_{\mathrm{N}}=\left\langle\hat{e}_{\mathrm{L} 1}\left(\hat{\mathrm{s}}_{11}\right), \ldots, \hat{\mathrm{e}}_{\mathrm{W}}\left(\hat{\mathrm{s}}_{11}\right), \ldots, \hat{e}_{\mathrm{N} 1}\left(\hat{\mathrm{s}}_{11}\right)\right), \forall h=2, \ldots, H, \forall k \neq \ell$. The market clearing price follows $\hat{p}=\rho\left(\hat{\mathrm{s}}_{i}, \hat{\mathrm{e}}_{\mathrm{i} i}, \ldots, \hat{\mathrm{e}}_{\mathrm{i} \alpha}\right)$. The SCE allocations are then

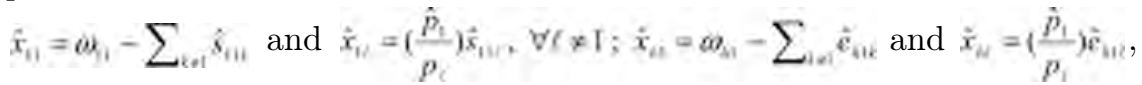

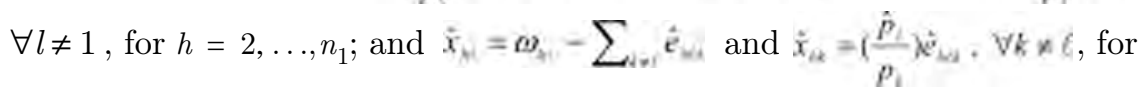
$h=n_{1}+1, \ldots, H$. Finally, the associated utility levels are $\hat{U}_{2}\left(\hat{x}_{\Delta}\right), \forall h$. We can now state a formal definition of the SCE:

Definition 2. A Stackelberg-Cournot equilibrium is given by a $H(L-1)$-tuple of strategies $\left(\hat{\mathrm{s}}_{11}, \hat{\mathrm{e}}_{21} \ldots . . \hat{\mathrm{e}}_{1}, \ldots . . \hat{\mathrm{e}}_{w}\right) \in \mathbb{R ^ { M ( L - T | }}$, a system of consistent market clearing prices $\hat{p}=p\left(\hat{\mathrm{s}}_{1 i}, \dot{\mathrm{c}}_{21}, \ldots, \hat{\mathrm{e}}_{i 2}\right)$ and an allocation $\left(\hat{x}_{1}, \ldots, \hat{x}_{k}, \ldots, \hat{x}_{N}\right) \in \mathbb{R} \mathbb{R}_{+}^{\prime \prime}$ such that the four following conditions hold:

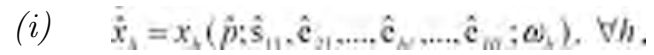

$$
\begin{aligned}
& \text { (ii) } \sum \hat{x}_{\mu}=\sum \omega_{\mu}, \forall 6 \text {, }
\end{aligned}
$$


(iii)

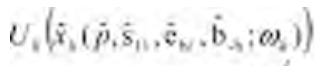

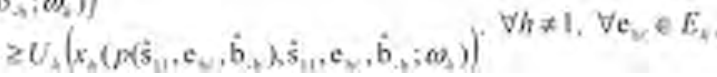

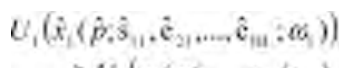

$$
\begin{aligned}
& \geq U_{1}\left(x_{1}\left(p\left(s_{11}, c_{11}\left(s_{11}\right), \ldots, c_{11}\left(s_{11}\right)\right) ; s_{11}, c_{31}\left(s_{11}\right), \ldots, c_{11}\left(s_{11}\right) ; \omega_{1}\right)\right)
\end{aligned}
$$

We suppose that the two equilibria previously defined exist and are unique. As already noted, the equilibrium concepts here proposed display a two-step sequential strategic structure, with a general market clearing condition. The existence of a general oligopoly equilibrium is not guaranteed in the general case (Cordella and Gabszewicz (1998), Gabszewicz (2002)), but can be demonstrated in the case of linear pure exchange economies (Bonnisseau and Florig (2003)).

\section{An example: a two-commodity economy}

Consider the following simple pure exchange economy as an example of the economy described in section 2. It includes two divisible consumption goods ( 1 and 2 ) and $n+2$ consumers. It is assumed that good 2 is taken as the numéraire, so $p$ is the price of good 1 as expressed in units of good 2 .

The preferences of every consumer are represented by the same utility function:

$$
U_{A}=x_{H_{1}} x_{A_{2}}, \forall h_{\text {. }}
$$

The structure of initial endowments in sector 1 and in sector 2 is assumed to be, respectively:

$$
\begin{aligned}
& \omega_{1}=(\alpha, 0) \text { and } \omega_{s}=(1-\alpha, 0), \text { with } \alpha \in(0,1), \\
& \omega_{s}=\left(0, \frac{1}{n}\right), h=3 \ldots, n+2
\end{aligned}
$$

The strategy set of each agent writes:

$$
\begin{aligned}
& S_{1}=\left\{s_{11} \in I R_{+} \mid 0 \leq s_{11} \leq \alpha\right\} . \\
& E_{2}=\left\{e_{21} \in I R_{+} \mid 0 \leq e_{31} \leq 1-\alpha\right\} . \\
& E_{e}=\left\{\varepsilon_{02} \in I R_{+} \mid 0 \leq \varepsilon_{32} \leq \frac{1}{*}\right\} \text { or } E_{n}=\{\}, h=3, \ldots n+2,
\end{aligned}
$$

where $s_{11}, e_{21}$ and $e_{h 2}$ respectively denote the pure strategy of the leader, of agent 2 and possibly of agent $h, h=3, \ldots, n+2$.

The leader then obtains in exchange of $s_{11}$ a quantity $p s_{11}$ of good 2 . The follower similarly obtains in exchange of $e_{21}$ a quantity $p e_{21}$ of good 2 . In the second sector, each agent $h, h=3, \ldots, n+2$, is either a price-taker or a Cournotian oligopolist. 
For this pure exchange economy, we compute the Stackelberg-Walras equilibrium (SWE), for which $E_{0}=\{\}, \forall h \neq 1.2$; and the Stackelberg-Cournot equilibrium (SCE), for which $E_{b}=\left\{e_{k_{2}} \in \mathbb{R} \mathbb{R}_{+} \mid 0 \leq e_{h_{2}} \leq \frac{1}{*}\right\}, \forall A \neq 1,2$. We then compare them with the Cournot equilibrium $(\mathrm{CE})$ and the CournotWalras equilibrium (CWE). We finally set up a ranking of exchange quantities and of prices involving these four strategic equilibria and the Walrasian equilibrium.

\subsection{The Stackelberg equilibria}

In the $S W E$ framework, it is considered that agents having endowments in good 2 act competitively, whereas the other agents behave strategically: agent 1 is the leader and agent 2 is the follower. Hence, each agent $h$, $h=3, \ldots, n+2$, will buy a quantity $z_{h 2} / p$ of $\operatorname{good} 1$, where $z_{h 2}$ is her $/$ his competitive supply of good 2. The story is solved by backward induction, considering first the behavior of the Walrasian agents, then the decision of the follower, and finally the choice of the leader.

The competitive plans of owners of good 2 is deduced from a non-strategic maximization of the utility function subject to the budget constraint, i.e. $A r g \max \left(\frac{1}{p} z_{n z}\right)\left(\frac{1}{n}-z_{k z}\right), h=3, \ldots, n+2$. From $(21)-(22)$, we deduce the competitive individual offer plan $z_{h 2}=1 /(2 n)$ and the demand functions $\left(x_{i,}, x_{42}\right)=\left(\frac{1}{2 n p}, \frac{1}{2 n}\right), f_{i}=3, \ldots, n+2$.

The aggregate demand in good 1 by owners of good 2 is $\sum_{n=1}^{i n z} x_{21}=1 / 2 p$. The equilibrium price is then given by $\frac{1}{2} p=s_{11}+e_{21}$, so $p=1 /\left(2\left(s_{11}+e_{31}\right) \mid\right.$.

The strategic plan of the follower is determined by two elements: $\mathrm{s} /$ he manipulates the market price and s/he takes the leader's strategy as given. Thus the follower's program writes:

$$
\operatorname{Arg} \max \frac{1}{2}(0-\alpha)-\varepsilon_{21}\left(\frac{\varepsilon_{21}}{s_{11}+\varepsilon_{21}}\right) \text {, }
$$

which gives the following reaction function:

$$
e_{21}\left(s_{11}\right)=\sqrt{s_{11}^{2}+(1-\alpha) s_{11}}-s_{91} .
$$

We can see that this function is continuous and increasing, with $\partial e_{2 i} / \partial s_{11}>0$ and $\partial^{2} e_{21} / \partial s_{11}^{2}<0^{10}$.

10 Moreover, we have âs $/ \partial \alpha<0$. 
The strategic plan of the leader is determined by two elements: she manipulates the market price and the follower's strategy. The leader thus solves the following program:

$$
\operatorname{Arg} \max \frac{1}{2}\left(\alpha-s_{11}\right)\left(\frac{s_{11}}{s_{11}+e_{21}\left(s_{11}\right)}\right) \text {. }
$$

which gives the following optimal strategy:

$$
\bar{s}_{11}=\frac{1}{4}|\phi-3(1-\alpha)| \text {. }
$$

where $\varphi=\sqrt{\left.(1-\alpha)^{9}-\alpha\right)}$, with $\varphi \in(0,3)^{11}$.

We can deduce the value of the follower's strategy $\widetilde{e}_{2 i}=e_{2 i}\left(\widetilde{s}_{i 1}\right)$ :

$$
\tilde{e}_{21}=\frac{1}{4}\{\psi-|\varphi-3(1-\alpha)|\} \text {. }
$$

where $\psi=\sqrt{(\varphi-3(1-\alpha))(\varphi+(1-\alpha))}$.

Since $z_{h 2}=1 /(2 n)$, it is now possible to determine the equilibrium price:

$$
\tilde{p}=\frac{2}{\psi} .
$$

The individual allocations are thus:

$$
\begin{gathered}
\left(\bar{x}_{11}, \vec{x}_{12}\right)=\left(\frac{1}{4}(3+\alpha-\varphi), \frac{\varphi-3(1-\alpha)}{2 \varphi}\right), \\
\left(\bar{x}_{21}, \bar{x}_{22}\right)=\left(\frac{1}{4}(\varphi-\varphi+(1-\alpha)), \frac{\varphi-[\varphi-3(1-\alpha)]}{2 \psi}\right), \\
\left(\bar{x}_{i 1}, \bar{x}_{b 2}\right)=\left(\frac{\psi}{4 n}, \frac{1}{2 n}\right), h=3, \ldots, n+2 .
\end{gathered}
$$

The associated utility levels are respectively:

$$
\begin{gathered}
\vec{U}_{1}=\frac{(3+\alpha-\varphi)(\varphi-3(1-\alpha))}{8 \psi}, \\
\vec{U}_{2}=\frac{(\varphi-\varphi+(1-\alpha))(\psi-\varphi+3(1-\alpha))}{8 \psi}, \\
\vec{U}_{1}=\frac{\psi}{8 n^{2}}, h=3, \ldots, n+2 .
\end{gathered}
$$

In the SCE framework, it is considered that all agents behave strategically, with agent 1 as the leader. The only difference with the previous case is that the agents endowed in good 2 behave oligopolistically. We denote $e_{h 2}$ the pure strategy of agent $h, h=3, \ldots, n+2$, with $e_{h 1} \in[0,1 / n]$. Thus, each agent $h$ obtains in exchange of $e_{h 2}$ a quantity $e_{h 2} / p$ of good 1 .

11 We have ${ }^{2} s_{i 1} / d \alpha>0$. 
The game is solved in two steps considering first the decisions of the $(n+1)$ Cournotian agents, and finally the choice of the leader.

The market price is given by $p=\frac{\sum_{i 1}^{2} e_{k z}}{s_{11}+e_{31}}$, which insures the market clearing $^{12}$.

Taking the $(n-1) e_{-h 2}, s_{11}$, and $e_{21}$ strategies as given, each strategist $h$ of sector 2 maximizes his/her utility:

$$
\operatorname{Arg} \max \left(\frac{\left(s_{11}+e_{21}\right)}{e_{k, z}+(n-1) e_{k, j}} e_{k z}\right)\left(\frac{1}{n}-e_{k z}\right), h=3, \ldots, n+2,
$$

which gives the following reaction function:

$$
e_{k 2}=\frac{n-1}{n(2 n-1)}, h=3, \ldots, n+2
$$

Taking the strategy $s_{11}$ and the $n$ strategies $e_{h 2}$ as given, the Cournotian follower of sector 1 maximizes her/his utility:

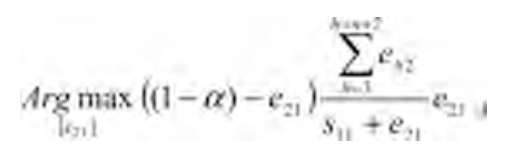

which gives the following reaction function:

$$
e_{2 i}\left(s_{10}\right)=\sqrt{s_{11}^{2}+(1-\alpha) s_{i 1}}-s_{13} .
$$

Considering the best responses of the followers, the leader maximizes her/his utility:

$$
\operatorname{Arg} \max \left(\alpha-s_{11}\right) \frac{\sum_{i=1}^{n+2} e_{2 i 2}^{2}}{s_{11}+e_{2 i}\left(s_{11}\right)} s_{11}=
$$

which gives the optimal strategy:

$$
\hat{s}_{11}=\frac{1}{4}|\phi-3(1-\alpha)| .
$$

The values of the Cournotian strategies follow:

$$
\begin{gathered}
\hat{c}_{21}=\frac{1}{4}\{\psi-|\varphi-3(1-\alpha)|\}, \\
\hat{e}_{k 2}=\frac{n-1}{n(2 n-1)}, h=3, \ldots n+2 .
\end{gathered}
$$

12 As we consider a two-good economy, the market clearing price mechanism used by Sahi and Yao (1989) and the market price mechanism used by Amir et al. (1991) are equivalent. 
The equilibrium price $\hat{p}=\frac{\sum_{t=1}^{b-2} \hat{e}_{n}}{\hat{s}_{11}+\hat{e}_{n i}}=\frac{4(n-1)}{(2 n-1)} \frac{1}{\psi}$ can be written:

$$
\hat{p}=\frac{2(n-1)}{2 n-1} \hat{p} \text {. }
$$

The individual allocations are thus:

$$
\begin{gathered}
\left(\hat{x}_{11}, \hat{x}_{12}\right)=\left(\vec{x}_{11}, \frac{2(n-1)}{2 n-1} \bar{x}_{12}\right) . \\
\left(\hat{x}_{21}, \dot{x}_{22}\right)=\left(\vec{x}_{21}, \frac{2(n-1)}{2 n-1} \vec{x}_{22}\right), \\
\left(\hat{x}_{41}, \hat{x}_{b 2}\right)=\left(\tilde{x}_{b 1}, \frac{2 n}{2 n-1} \bar{x}_{h 2}\right), h=3, \ldots, n+2 .
\end{gathered}
$$

The utility levels reached are respectively:

$$
\begin{gathered}
\hat{U}_{1}=\frac{2(n-1)}{2 n-1} \hat{U}_{1}, \\
\hat{U}_{2}=\frac{2(n-1)}{2 n-1} \hat{U}_{2}, \\
\hat{U}_{4}=\frac{2 n}{(2 n-1)} \bar{U}_{h}, h=3 \ldots \ldots n+2 .
\end{gathered}
$$

Result 1. When the number of agents tends to infinity, the StackelbergCournot equilibrium converges to the Stackelberg-Walras equilibrium.

Proof. We have to show that the equilibrium price and optimal allocations in sector 2 converge toward the Stackelberg-Walras one when $n$ becomes large. For the equilibrium price, we have $\lim _{n+(}\left(\frac{2(n-1)}{2 n-1}\right) \bar{p}=\bar{p}$. For the individual allocations, as $\left(\hat{x}_{1,}, \hat{x}_{n 2}\right)=\left(\hat{x}_{11}, \frac{2\langle n-1)}{2 n-1} \vec{x}_{\square}\right)$ for the leader, $\left(\hat{x}_{21}, \hat{x}_{22}\right)=\left(\bar{x}_{21}, \frac{2(n-1)}{2 n-1} \bar{x}_{22}\right)$ for the second agent and $\left(\hat{x}_{k 1}, \hat{x}_{k 2}\right)=\left(\vec{x}_{k n}, \frac{2 n}{2 n-1} \vec{x}_{h 2}\right)$ for $h=3, \ldots, n+2$, it is obvious that $\lim _{n \rightarrow \infty}\left(\hat{x}_{11}, \hat{x}_{22}\right)=\left(\tilde{x}_{11}, \widetilde{x}_{12}\right)$ for the leader, $\lim _{i n \rightarrow-\infty}\left(\hat{x}_{21}, \hat{x}_{22}\right)=\left(\hat{x}_{21}, \hat{x}_{22}\right)$ for the second agent and that $\lim _{a \rightarrow+\infty}\left(\hat{x}_{31}, \hat{x}_{i 2}\right)=\left(\hat{x}_{i 2}, \vec{x}_{k 2}\right)$ for $h=3, \ldots, n+2$. This completes the proof.

Result 1 is classical, but here extended to a Stackelbergian context. The market power of each oligopolist decreases when the number of agents increases unboundedly. Hence, when $n$ goes to infinity, the Cournotian behavior tends to the Walrasian one. 
Result 2. There is no Pareto domination between the Stackelberg-Walras and the Stackelberg-Cournot equilibria.

Proof. From (48), (49) and (50) we have $\hat{U}_{1}=\frac{2(n-1)}{2 n-1} \hat{U}_{1}, \hat{U}_{2}=\frac{2(n-1)}{2 n-1} \vec{U}_{3}$ and $\hat{U}_{k}=\frac{2 n}{2 n-1} \widetilde{U}_{n}, h=3, \ldots, n+2$. As $\frac{2(n-1)}{2 n-1}<1$ and $\frac{2 n}{2 n-1}>1$, we have $\widetilde{U}_{1}>\hat{U}_{1}, \widetilde{U}_{2}>\hat{U}_{2}$ and $\tilde{U}_{4}<\hat{U}_{4}, h=3, \ldots, n+2$. This completes the proof.

Result 2 comes from two elements. Strategic agents of the first sector do better when they face competitive agents than when they struggle with strategic agents. But those agents of the second sector compete better under a Cournotian behavior than under a Walrasian one.

\subsection{The Stackelberg equilibria and the Cournot equilibria}

We now make welfare comparisons between the two Stackelberg equilibria and Cournot equilibria. We consider two concepts of those equilibria: the Cournot-Walras equilibrium (CWE) and the Cournot equilibrium (CE).

Let's first remind the logic of the Cournot-Walras equilibrium. This equilibrium concept has been introduced by Codognato and Gabszewicz (1991), (1993) for pure exchange economies. The oligopolists try to manipulate the price by restricting their supply and the many other agents behave competitively. The story is solved by backward induction. In the first step, the competitive equilibrium is computed for given strategies; in the second step, the equilibrium strategies are determined. A CWE is a non cooperative equilibrium of a game where the players are the oligopolists, the strategies are their supply decisions and the payoffs are their utility levels.

In this two-good example, the oligopolists are the suppliers of good 1 and the competitive agents are the suppliers of good 2. The CWE is thus given by a pair of optimal strategies $\left(\bar{\varepsilon}_{1 i}, \bar{\varepsilon}_{21}\right)$, with $\bar{\varepsilon}_{11} \in[0, \alpha]$ and $\vec{e}_{11} \in[0,1-\alpha]$, and an allocation $\left(\hat{x}_{1}, \hat{x}_{2}\right) \in I R^{\prime}$ such that $(i) \bar{x}_{1}=x_{1}\left(\hat{\varepsilon}_{11}, \hat{e}_{21}\right)$ and $\hat{x}_{2}=x_{2}\left(\hat{\varepsilon}_{11}, \hat{\varepsilon}_{21}\right)$ and (ii) $U_{1}\left(x_{1}\left(\hat{e}_{11}, \bar{e}_{21}\right)\right) \geq U_{1}\left(x_{1}\left(e_{11}, \bar{e}_{21}\right)\right)$ and $U_{2}\left(x_{1}\left(\hat{e}_{11}, \hat{e}_{21}\right)\right) \geq U_{2}\left(x_{2}\left(\hat{e}_{11}, \hat{e}_{21}\right)\right)$, where $e_{11}$ and $e_{21}$ denote the strategies of agent 1 and agent 2 . It is possible to state the following result:

Result 3. When $\alpha=1 / 2$, there is no Pareto domination between the Stackelberg-Walras equilibrium and the Cournot-Walras equilibrium.

Proof. The CWE is relevant when $\alpha=1-\alpha$, so $\alpha=1 / 2$. For this value, agents 1 and 2 have the same preferences and endowments, and this might be a justification of their acting the same way. If $\alpha=1 / 2$, then $\varphi=\sqrt{17} / 2$ 
and $\psi=\sqrt{(7-\sqrt{17}) / 2}$. We compute the CWE for the economy described by (21)-(23) for these values and compare these results with those obtained for the SWE.

The equilibrium price satisfies $\sum_{i=1}^{\mathrm{k} * * 3}[1 /(2 n p)]=\varepsilon_{1 j}+\varepsilon_{21}$, so $p=1 /\left[2\left(\varepsilon_{11}+c_{s}\right)\right]$. The non-cooperative equilibrium is associated with the resolution of the simulta-

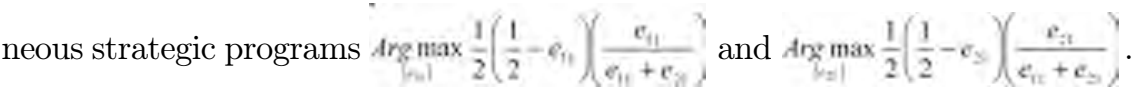
The equilibrium strategies are $\hat{e}_{14}=1 / 6$ and $\hat{e}_{21}=1 / 6$. We thus have $\bar{p}=3 / 2$. The individual allocations and the associated utility levels for each agent can respectively be written $\left(\bar{x}_{11}, \bar{x}_{12}\right)=(1 / 3,1 / 4)$ and $\hat{U}_{1}=1 / 32$ for agent 1 , $\left(\bar{x}_{21}, \bar{x}_{22}\right)=(1 / 3,1 / 4)$ and $\bar{U}_{1}=1 / 12$ for agent 2 , and $\left(\bar{x}_{41}, \bar{x}_{i 2}\right)=(1 /(3 n), 1 /(2 n))$ and $\bar{U}_{4}=1 /\left(6 n^{2}\right)$ for $h=3, \ldots, n+2$. Then $\theta_{1}-\bar{U}_{1}-\frac{1}{8} \sqrt{\frac{7}{2}-\frac{\sqrt{17}}{2}}\left(\frac{\sqrt{17}}{2}-\frac{3}{2}\right)-\frac{1}{12}>0$ for agent $1, \bar{U}_{2}-\bar{U}_{2}=\frac{1}{8} \sqrt{\frac{2}{7-\sqrt{17}}}\left(\frac{\sqrt{17}}{2}-\sqrt{\frac{7-\sqrt{17}}{2}}+\frac{1}{2}\right)\left(-\frac{\sqrt{17}}{2}+\sqrt{\frac{7-\sqrt{17}}{2}}+\frac{3}{2}\right)-\frac{1}{12}<0$ for agent 2 and $\vec{U}_{4}-\vec{U}_{6}=\frac{1}{8 n^{2}} \sqrt{\frac{7}{2}-\frac{\sqrt{17}}{2}}-\frac{1}{6 n^{2}}<0$ for $h=3, \ldots, n+2$. This completes the proof.

Three different points can be emphasized. Firstly, confronted to a Cournotian competitor, agent 1 is better off playing as a leader than as a follower. Secondly, Cournotian agent 2 is better off confronted to a follower à la Cournot than to a leader à la Stackelberg. Thirdly, Walrasian agents are better off facing a Cournotian competition than facing a Stackelbergian competition, as the latter involves a stronger contraction of the oligopolistic supply.

Let's now introduce the Cournot equilibrium (CE). Here all agents behave strategically in a Cournotian way, as formalized in the theory of strategic market games by Shapley and Shubik (1977) or by Sahi and Yao (1989). A CE can thus be defined as a $(n+2)$-tuple of strategies $\left(\bar{e}_{11}, \bar{e}_{21}, \bar{e}_{22}, \ldots, \bar{e}_{n+22}\right)$, with $\bar{e}_{11} \in[0, \alpha], \bar{e}_{21} \in[0,1-\alpha]$ and $\bar{e}_{k 2} \in[0,1 / n]$ for $h=3, \ldots, n+2$, and an allocation $\left(\bar{x}_{1}, \bar{x}_{2} \ldots, \bar{x}_{k-1}\right) \in I R_{-}^{\times \cdots ?}$ such that (i) $\bar{x}_{\Delta}=x_{\Delta}\left(\bar{c}_{k}, \bar{e}_{-4}\right) \forall h$ and (ii)

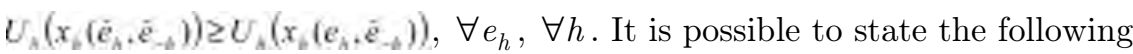
result: 
Result 4. When $\alpha=1 / 2$, the Stackelberg-Cournot equilibrium is Pareto dominated by the Cournot equilibrium.

Proof. Under the Cournot equilibrium assumption, the market clearing

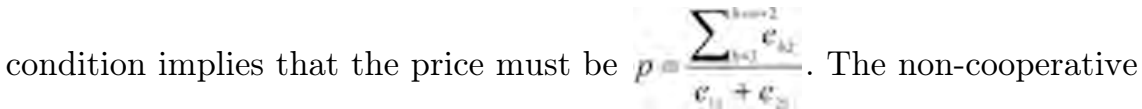
equilibrium is associated with the resolution of the simultaneous strategic programs Argmax $\left(\frac{1}{2}-\varepsilon_{11}\right)\left(\frac{e_{2}}{e_{1}} \varepsilon_{11}\right)$ for agent $1, \operatorname{Arg} \max \left(\frac{1}{2}-\varepsilon_{231}\right)\left(\frac{e_{2}}{e_{1}} e_{2 y}\right)$ for agent 2 and $\operatorname{Arg} \max \left(\frac{e_{1}}{e_{2}} e_{n z}\right)\left(\frac{1}{n}-e_{n z}\right)$ for agent $h, h=3, \ldots, n+2$. The $(n+2)$ conditions of optimality, i.e. $\partial U_{1} / \partial e_{1}=0$ for agent $1, \partial U_{2} / \partial v_{y_{1}}=0$ for agent 2 and $\partial V_{A} / \lambda v_{k 2}=0$ for $h=3, \ldots, n+2$, yield the optimal strategies $\tilde{e}_{1 i}=\tilde{e}_{21}=1 / 6$ and $\tilde{e}_{n z}=(n-1) /[n(2 n-1)]$. We deduce the CE price $\bar{p}=\frac{3(n-1)}{2 n-1}$. The individual allocations are $\left(x_{11}, x_{12}\right)=\left(\frac{1}{3}, \frac{n-1}{2 n-1}\right)$ for agent 1 , $\left(\tilde{x}_{3}, \tilde{x}_{n}\right)=\left(\frac{1}{3}, \frac{n-1}{2 n-1}\right)$ for agent 2 and $\left(\tilde{x}_{n+1}, \bar{x}_{k z}\right)=\left(\frac{1}{3 n}, \frac{1}{2 n-1}\right)$ for agent $h$, $h=3, \ldots, n+2$. The utility levels reached by each type of consumers are then $U_{1}=\frac{n-1}{3(2 n-1)}$ for agent $1, U_{2}=\frac{n-1}{3(2 n-1)}$ for agent 2 and $U_{3}=\frac{1}{3 n(2 n-1)}$ for agent $h, h=3, \ldots, n+2$. We have $\hat{U}_{s}-\bar{U}_{c}=\frac{2(n-1)}{2 n-1}\left(\widetilde{U}_{b}-\frac{1}{6}\right)<0$ since $\widetilde{U}_{4}<1 / 6$ for $h=1,2$. And, we have $\hat{U}_{4}-\bar{U}_{4}=\frac{2 n}{2 n-1}\left(\tilde{U}_{4}-\frac{1}{6 n^{2}}\right)<0$ since $\vec{U}_{0}<\frac{1}{6 n^{2}}$ for $h=3, \ldots, n+2$. This completes the proof.

The study of welfare comparisons engages four types of equilibrium. Three kinds of behavior are put forward by these equilibria: the leader is strongly strategic (s/he considers the influence of her/his action on all the others), the follower is weakly strategic (s/he takes the strategic actions of others as given) and the competitive agents have a parametric behavior. The comparison displayed by Result 2 shows that, when agents owning good 2 turn from a competitive behavior to a Cournotian one, they are better off and the others are worse off. The comparison displayed by Result 3 shows that, when agent 1 turns from a Cournot behavior to a Stackelberg one, her/his welfare is higher and the ones of the others are worse off. These results could support the idea that an agent is better off and the others are worse off when s/he turns from a competitive behavior to a Cournotian one, or from a following behavior to a leading behavior. Result 4 actually provides a counter-example of this idea: turning from a Cournot behavior to a Stackelberg behavior may be damaging for the first agent, when s/he and 
the second agent are identical in terms of endowments and when the other agents do not behave as price takers. This can be explained by the stronger restriction of the supply of good 1 (for both agents) necessary to get a more advantageous relative price, when agents owning good 2 are not price takers.

\subsection{The strategic equilibria and the competitive equilibrium}

Let us now compute the competitive equilibrium. From (21)-(22), we determine the equilibrium relative price $p^{*}=1$, the equilibrium individual allocations $\left(x_{11}^{*}, x_{12}^{\prime}\right)=\left(\frac{\alpha}{2}, \frac{\alpha}{2}\right),\left(x_{y}^{*}, x_{22}^{*}\right)=\left(\frac{1-\alpha}{2}, \frac{1-\alpha}{2}\right)$ and $\left(x_{i 1}^{*}, x_{i 2}^{\prime}\right)=\left(\frac{1}{2 n}, \frac{1}{2 n}\right)$, $h=3, \ldots, n+2$. The corresponding payments are thus $U_{i}=\left(\frac{\alpha}{2}\right)^{?}$ $U_{i}=\left(\frac{1-\alpha}{2}\right)^{2}$ and $\hat{U}_{4}=\left(\frac{1}{2 n}\right)^{2}, h=3, \ldots, n+2$.

Result 5. When $\alpha=1 / 2$, the price rankings are $p^{*}<\hat{p}<\hat{\rho}$ and $p^{*}<\bar{\rho}<\bar{p}$, while the quantity rankings are $y_{1}^{\prime}>\bar{y}_{1}=\hat{y}_{1}>\hat{y}_{1}=\tilde{y}_{1}$ and $\hat{y}_{2}^{\prime}=\hat{y}_{2}=\tilde{y}_{2}>\hat{y}_{2}=\hat{y}_{2}$.

Proof. Suppose $\alpha=1 / 2$. Let us denote by $y_{1}$ and $y_{2}$ the traded quantities of good 1 and 2 , with $y_{1}=1-x_{11}-x_{21}$ and $y_{2}=1-n x_{h 2}$. The competitive equilibrium price and allocations are $p^{*}=1,\left(x_{11}^{*}, x_{22}^{*}\right)=\left(\frac{1}{4}, \frac{1}{4}\right)$, $\left(x_{21}^{\prime}, x_{22}^{*}\right)=\left(\frac{1}{4}, \frac{1}{4}\right)$ and $\left(x_{i 1}^{*}, x_{k 2}^{\prime}\right)=\left(\frac{1}{2 n}, \frac{1}{2 n}\right), h=3, \ldots, n+2$. Then $y_{1}^{*}=\frac{1}{2}$ and $y_{2}=\frac{1}{2}$. For the SWE, we have $\tilde{p}=2 \sqrt{\frac{2}{7-\sqrt{17}}}$, with $\sqrt[2]{\frac{2}{7-\sqrt{17}}}$, $\hat{y}_{1}=\frac{1}{4} \sqrt{\frac{7-\sqrt{17}}{2}}$ and $\hat{y}_{2}=\frac{1}{2}$. For the SCE, we have $\hat{p}=\frac{2(n-1)}{2 n-1} \hat{p}_{1} \tilde{y}_{1}=\bar{y}_{1}$ and $\hat{y}_{2}=\frac{n-1}{2 n-1}$. For the CWE, we verify $\hat{p}=\frac{3}{2}, \bar{y}_{1}=\frac{1}{3}$ and $\bar{y}_{2}=\tilde{y}_{2}$. Finally, the CE yields $\vec{p}=\frac{3(n-1)}{2 n-1}, \vec{y}_{1}=\hat{y}_{1}$ and $\bar{y}_{2}=\hat{y}_{3}$. This completes the proof.

The quantity ranking in good 1 shows that the supply restriction in good 1 is higher when agent 1 acts as a leader. The quantity ranking in good 2 reflects that when agents endowed in this good behave as price-takers, the traded quantity is bigger than when they act strategically. The price rankings reveal that agents of sector 1 can get a better price when they face competitive agents on the other side of the market. 


\section{Conclusion}

Whereas the Cournot-Walras and the Cournot equilibria imply only one kind of strategic behavior, the Stackelberg-Walras and the StackelbergCournot equilibria involve two types of strategic behavior: one for the leader and one for the follower. Additionally, the SWE displays three types of decision making: the pure competitive one, the pure monopolistic one and the strategic/parametric one, while the SCE involves two types of decision making.

The investigation devoted to the different kinds of strategic behavior could be extended for the SWE, making endogenous the competitive behavior, as the consequence of a Cournotian game (see Busetto et al. (2008)). We could also consider a continuum of agents holding good 2, which would lead to an equivalence between the SWE and the SCE.

The robustness of welfare comparison results could be tested using another specification for the utility function. We could also compute the different equilibria in a three-good economy with several followers holding $\operatorname{good} 1$.

Further developments about competition à la Stackelberg under general equilibrium analysis could tackle the question of the multiplicity of leaders or extend the framework to an economy with production.

\section{References}

Amir R., I. Grilo (1999), "Stackelberg versus Cournot equilibrium", Games and Economic Behavior, 36, pp. 1-21.

Amir R., S. Sahi, M. Shubik and S. Yao (1990), "A strategic market game with complete markets", Journal of Economic Theory, 54, pp. 126-143.

Anderson S.P., and M. Engers (1992), "Stackelberg versus Cournot equilibrium", International Journal of Industrial Organization, 10, pp. 127-135.

D'Aspremont C., R. Dos Santos Ferreira and L.A. Gérard-Varet (1997), "General equilibrium concepts under imperfect competition: a Cournotian approach", Journal of Economic Theory, 173, pp. 199-230.

Bonnisseau J.M., and M. Florig (2003), "Oligopoly equilibria in large, but finite, linear exchange economies", Economic Theory, 22, p. 727-741.

Busetto F., G. Codognato and S. Ghosal (2008), "Cournot-Walras equilibrium as a subgame perfect equilibrium", International Journal of Game Theory, 37, pp. $371-386$.

Codognato G., and J.J. Gabszewicz (1993), "Cournot-Walras equilibria in markets with a continuum of traders", Economic Theory, 3, pp. 453-464. 
Codognato, G., J.J. Gabszewicz (1991),"Equilibres de Cournot-Walras dans une économie d'échange pure", Revue Economique, 42, pp. 1013-1026.

Codognato, G., S. Ghosal (2000), "Cournot-Nash equilibria in limit exchange economies with complete markets and consistent prices", Journal of Mathematical Economics, 34, pp. 39-53.

Cordella, T. and J.J. Gabszewicz (1998), "Nice trivial equilibria in strategic market games", Games and Economic Behavior, 22, pp. 162-169.

Friedman, J. (1993), "Oligopoly theory", in K.J. Arrow and M.D. Intriligator (Eds), Handbook of Mathematical Economics, Elsevier, chapter 11, Volume 2, pp. 491-534.

Fudenberg D., J. Tirole (1991), Game theory, MIT Press.

Gabszewicz, J.J. (2006), "Oligopoly equilibrium in pure exchange economies", Games theory and Mathematical Economics, 71, pp. 125-135.

Gabszewicz, J.J. (2002), Strategic multilateral exchange, general equilibrium with imperfect competition, Edward-Elgar, Cheltenham.

Gabszewicz, J.J., P. Michel (1997), "Oligopoly equilibria in exchange economies", in B.C. Eaton and R.G. Harris (Eds), Trade, Technology and Economics. Essays in Honour of R.G. Lipsey, Edward-Elgar, Cheltenham, pp. 217-240.

Gabszewicz, J.J., J.P. Vial (1972), "Oligopoly 'à la Cournot' in a general equilibrium analysis", Journal of Economic Theory, 4, pp. 381-400.

Giraud, G. (2003), "Strategic market games: an introduction", Journal of Mathematical Economics, 39, pp. 355-375.

Kreps D. (1990), Game theory and economic modelling, Clarendon Lectures in Economics.

Sahi S., S. Yao (1989), "The non cooperative equilibria of a trading economy with complete markets and consistent prices", Journal of Mathematical Economics, 18, pp. 325-346.

Shapley, L., M. Shubik (1977), "Trade using one commodity as a means of payment", Journal of Political Economy, 85, pp. 937-967.

von Stackelberg H. (1934), Marktform und Gleichgewicht, Berlin \& Vienna, Springer.

Tirole J. (1988), Theory of industrial organization, MIT Press.

Vives X. (1999), Oligopoly pricing: olds ideas, new tools, MIT Press. 